\title{
Whatever happened to Tuatapere? A study on a small rural community
}

\section{Pam Smith}

Pam Smith has worked in the social work field for the past 25 years. She has worked with children and families within the community both in statutory and non-government organisations. She has held social worker and supervisor roles and is currently a supervisory Team Leader at Family Works Southland. This article was based on Pam's thesis for her Master of Philosophy in Social Work at Massey University.

\section{Abstract}

Social workers working in the rural community do so within a rural culture. This culture has developed from historical and cultural influences from the generations before, from the impact of social and familial changes over the years and from current internal and external influences. These changes and influences make the rural people who they are today.

This study was carried out on a small rural community in Western Southland. The purpose was to examine the impact on the community of social changes over the past 50 years. Eight long-term residents were interviewed. The results will be discussed within this article.

\section{Introduction}

Government policies, changes in international trade and markets, environmental policies, globalisation, change in the structure of local and regional government and legislative changes, impacted on all New Zealanders during the past 50 years. The rural hinterland of New Zealand was affected in particular ways.

The population in rural communities has been slowly decreasing over the years as urbanisation has been a reality in New Zealand. Services within the area have diminished and younger families have moved away to seek employment elsewhere. The remaining residents are an ageing population. This brings with it a range of interesting issues for the community. The elderly have to travel for their health and other service needs and the unavailability of regular daily transport services makes it difficult for them to meet appointments. They have to rely on family and friends for transport and many no longer have the family available to support them locally.

The township chosen for this study is Tuatapere on the south west corner of southern New Zealand. I grew up in the district and witnessed the changes from a flourishing timber and farming service centre to a quaint tourist town. The residents and how these changes impacted on their lives are explored in this study through the eyes of eight long-term residents. This is a qualitative study in which four men and four women were interviewed using a semi-structured questionnaire exploring their views on social change, the way the 
community has responded to changes in service provision and how they have managed the move from being a vibrant rural service community to a tourist town.

This study celebrates the individuals' successes, tells of their hardships, explores their attitudes to change, records their life work choices and decision making. Five themes were identified from the literature and provide a framework for this study: historical influences and cultural expectations, impact of government decisions on their lives, sense of community, sense of self and access to services.

\section{Methodology}

This study used the life story method in narrative form to gather reflections about social change over the past 50 years. The resulting oral histories assist workers to understand the communities in which they work. From the stories the social workers gain meaning and insight into the residents' culture and world view. What is being told is important because it relates past thoughts and experiences, and shapes who we are today and have meaning and significance for us.

\section{Ethical issues}

Full clearance for the research was obtained from the Massey University Human Ethics Committee. The participants were known to my family and me, therefore that relationship could not be ignored. As social change over the past 50 years was being researched, the participants were aged 60 years and over. The type of study that it was, being life stories from a small rural area, made it difficult, if not impossible, to guarantee confidentiality. This was clearly explained to the participants prior to gaining consent. All agreed to the use of their names.

\section{The interviewees}

Margaret

Margaret is in her early 60s and lives in her own home. She has a family of three adult children and works in the secondary section of the local community college. Margaret's father came to Tuatapere along with his mother and father from Hungary in 1912.

Helen

Helen is in her late 60s and came to Tuatapere as a teenager in the 1950s to teach Highland dancing. She married a local farmer and had a family of five. She owns a café on the main street of Tuatapere and now lives in the township. She married into a family, who like Helen, identify strongly with their Scottish roots.

\section{Hugh}

Hugh is in his early 80 s and is a retired farmer. He lives with his wife in the Tuatapere township. Hugh is the grandson of one of the first European settlers to Tuatapere. Hugh's son farms the family farm.

Robin

Robin is an electrician in his early seventies. He is a widower and has a grown up family. $70 \mathrm{~s}$ 
Bill

Bill is a retired farmer in his 70s who lives with his wife. They have a grown up family and the son farms the family farm on the outskirts of Tuatapere.

\section{Ngarita}

Ngarita, a widow, is 80 years old and lives on her own. Ngarita's husband owned a family sawmilling business. She has two grown daughters, one who lives in a country district nearby and the other in Auckland. Ngarita has been involved in local-body activities for a greater part of her life.

\section{Donald}

Donald is 60 and owns a farm on the outskirts of Tuatapere. He is married with a grown up family. A daughter is married and lives nearby.

June

June lives with her husband and is in her early 60s. They both work in businesses in and near Tuatapere. They have a married daughter living nearby. June's husband is a member of the local district council.

\section{Background}

The history of Tuatapere and its different cultures goes back to early Māori settlement.

Māori settled in the Tuatapere area following the arrival of the legendary 'Takitimu' canoe which entered Te Wae Wae Bay and was swamped by waves near the mouth of the Waiau River. People on board the canoe settled in the area and many of their descendants are still resident in the Tuatapere area (Southland District Council, 1995).

Following Māori settlement in the area other cultures arrived. Tuatapere developed initially as 'a sawmilling, flaxmilling and bush farming settlement ... the mix of cultures included Māori, Scottish, Irish, Welsh, Hungarian, Dutch, Polish, Australian and other components' (Southland District Council, 1995, p. 5). Many had come from the goldfields both within the area and from the outer areas. Tuatapere and indeed a great part of Southland's rural farming community were settled during the 19th and earlier part of the 20th centuries by mainly Scottish farmers and labourers.

From the early settlement period and up to 50 years ago Tuatapere's main industry was logging of the local indigenous forests. This provided employment in the logging and milling industries. At one stage over the years there were 120 sawmills in Tuatapere and its peripheries (Templeton, 1995). In 1987 the restructuring of the Forest Service and sawmilling industry occurred. At the beginning of 2008 there were just two sawmills, a family-owned business and a multi-national firm. Today the larger firm is the only one operating.

The lack of local industries has had a significant effect on the community. Families moved to find employment elsewhere. The number of residents aged 40 years and over has been steadily increasing, despite the decrease in the total population of Tuatapere (Statistics NZ, 2006). 
Figure one. Population of Tuatapere 1971-2006.

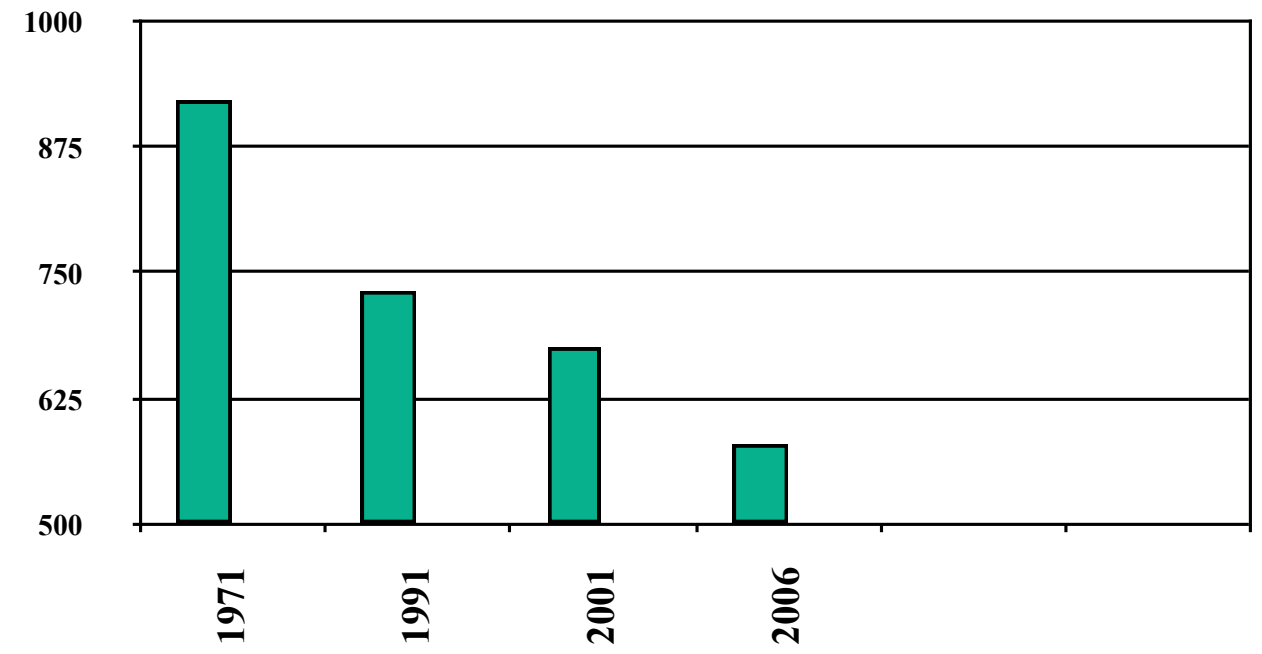

During 1994 the local community board in Tuatapere along with the District Council called a public meeting to consider the type of community the residents would like to see developing in the Tuatapere area in the future (Southland District Council, 1995). As a result amongst other ideas a promotional video was completed and circulated to promote the Tuatapere area. Search and rescue beacons were purchased and made available for trampers and hunters and an overall theme 'On Nature's Edge' was created. Amongst the projects identified was a major undertaking to establish a walking track called 'The Hump Track' that includes the historic Port Craig viaducts. This has been successfully achieved to the credit of the local people.

\section{The interviews}

\section{Historical and cultural influences and expectations}

Seven of the eight residents interviewed identified connections to Scottish or Northern Ireland parents or grandparents. Scottish practices still continue within the community.

One of the participants in the study and her husband teach Highland dancing and piping.

A commitment to the community especially in the ability to give voluntarily of their time was identified as being an expectation passed down from the parents. This volunteer expectation continues in the lives of participants interviewed. These shared values determine the culture of rural Tuatapere residents. 'Culture is learned and transferred from generation to generation' (Connolly, Crichton-Hill \& Ward, 2006, p. 20). The participants clearly showed an expectation that their children and grandchildren would carry on their values, beliefs and practices.

The culture of the participants' parents and grandparents' place of birth was not the only influence on the residents during the past 50 years. A strong male-dominated society existed 
especially within the rural areas that focused on working the land and other manual work. This was seen as the socially constructed environment of the time rather than the inherited culture (James \& Saville-Smith, 1989). The influences of the parents particularly the father was observed and discussed by Margaret and Ngarita. Both saw strengths in their parents that they admired. Margaret however saw her mother emerging in her own right in later life on her own. 'Mum was always involved in one thing, Women's Division. In her latter life she was very active in her own right. Up until then she was a shadow of Dad's.' Both fathers showed the authority of the male of the household as was the norm during those earlier times.

The residents felt that the definition of culture was changing. Although the Scottish practices may still be in place it is a changed society and new values are emerging. The old value systems and structures such as the nuclear family unit and the practices and beliefs of the young people, have changed. Ngarita said, 'There is a young wild teenage culture existing in Tuatapere at the moment.' Helen lamented,' I just hope that people started to search themselves and get back into it (their Scottish culture). So we are cultureless. In a vacuum.' Helen views the need to identify and hold onto the culture of their ancestors as being very important.

From the discourses and shared stories and views, new courses of action and beliefs are emerging. 'But to those who hold onto their cultural heritage perhaps it is unsurprising that the unfamiliar terrain of the emerging culture is perceived as the enemy and resistance is a natural response to the threat of change' (Howden, 2001, p. 14). Some of the cultural beliefs and historical influences passed down from the earlier generations to the present day residents have survived and some have disappeared. New social practices are appearing especially with the youth. From a post structural perspective not all these practices are seen in a positive light by the older residents. They still hold fast to their own belief systems and trust that they will be absorbed by the young as they grow and become part of the Tuatapere community.

\section{Impact of government decisions}

The participants' beliefs, influenced by their cultural and historical pasts, are affected by an environment influenced by socio-political decisions made at local and national government levels. The economic downturn in the 1980s and the restructuring of the Forest Service in 1987 (Houghton, King \& Piper, 1996), was identified by the participants as disastrous for the township and community. 'Those residents in rural places 65 and over have a lived experience based on economic dominance of rural productivity in all but the last decade of their lives' (Joseph \& Chalmers, 1995). As this comment was made over 10 years ago that could now read 'the last two decades of their lives'.

The depopulation that followed those economic and political decisions had a detrimental effect on the remaining residents of the township and their livelihood. Shops, banks and the post office were closed, school rolls diminished and a threat was made to close the maternity hospital and general medical service, these being clear signs of the reluctant welfare state (Shirley, 1994). All the participants referred to these outcomes and commented on the despair felt by the residents about the changes to their township.

Helen said, 'It ruined the town and then all our young people up and left and either went further afield in New Zealand or most of them went to Australia and they haven't 
come back.' Ngarita stated, 'The biggest influence has been the closing down of the forestry. That impacted on Tuatapere. And it is still impacting. We haven't grown through it yet. It took a whole strata of society out. The mums and dads and the kids at school. They had to leave to get work.' Due to government decisions made, the moving away of a section of the community gave those who were left behind a sense that they were being depleted of valuable resources that had once assisted the functioning of the town.

Another central government decision that impacted on the town was the lowering of the Waiau river that flows through the centre of the town. Meridian Energy paid compensation to the residents but at a cost to the environment. This decision to lower the Waiau was described by the participants as having a detrimental effect on the coastal beaches, the quality of the water and the water sports activities previously enjoyed by the inhabitants.

These decisions made by those in positions of power, the policy makers and politicians, gave the residents the perception of being unfairly treated. This does not necessarily mean that the powerless see themselves as victims. Often the very opposite occurs as they can be empowered by their own energy to challenge the decisions and actions that are being thrust upon them. In the Tuatapere residents' case they took the challenge head on and met the changes imposed upon them. They formed groups and held meetings to discuss options available to them as a response to the now residual role of the welfare state (Boston \& Dalziel, 1992).

The community rallied together and formed a Promotions Group and initiated a series of meetings to explore options for the township and surrounding areas. Tourism was the main topic for consideration. Several initiatives were the result, the most important being the establishment of the Hump Track. 'All these ideas came from this Promotions Group; the Southern Scenic Route, the saving of the viaducts and the Hump Track. Now the Promotions Group is working on a cycle trail on the west side of the Waiau between here and Te Anau,' stated Ngarita. Horticulture was also explored.

The health services were also threatened by the restructuring of the health system in the 1980s (Boston \& Dalziel, 1992). With the threat made by the Health Board to close the local maternity hospital and change the way of funding the local doctor, the Tuatapere community formed a trust for the establishment of a medical centre and the continuation of the maternity hospital

The participants in the study identified a disastrous period for their township following the government decisions and the economic downturn of the 1980s. This led to closure of businesses and depopulation. What followed was a township determined to retain their identity and livelihood. They formed groups and pursued other ventures for their township. They acknowledged a frustration at the bureaucratic decisions made that in most cases they believed were unreasonable and delayed or halted their progress. The efforts that were expounded showed that the inherent values, the shared community ethos and the determinedness not to be 'done to' resulted in a community that remains proud of their new image.

\section{Sense of community}

A sense of community differs depending on the experiences, thoughts and feelings of the inhabitants. Some saw community as their physical location while others viewed it by how 
they saw themselves interacting with others within their locality. The social structures within the community such as educational and sporting facilities enabled the people to have contact with others and thereby maintain a sense of community.

\section{Importance of physical location}

The physical sense of community is seen by the participants as their geographical surroundings. Ngarita stated:

Remember that is our geographical position. We have the Longwoods here and the Takis there and we've got the sea here so we didn't have anyone else to help us. We were on our own ... Yes we had to become resilient because Riverton couldn't help us and Otautau was over the hill, we always thought of Otautau over the hill, so they couldn't help us, they were always looking towards Invercargill not back to us. We had to help ourselves.

The individual within the environment strives to adapt to their changing world. The changes in their social and economic world are balanced by the reality of their physical surroundings. The geographical positioning of the Tuatapere community with the mountain ranges on one side and the sea on the other hindered support and interaction from neighbours. The physical isolation of their rural country township made it difficult for them to have access with the outside world and the tourist dollar. From the Tuatapere study the geographical isolation was reported as being a major attraction for some. It was reported that those people from densely populated areas, England, Brisbane, Auckland, found the isolation attractive and some came to settle in the area.

\section{Shared activities}

Participants also portray their sense of community through the shared activities they engaged in. These activities can be in a sports club, attending church or participating in a voluntary capacity. Ngarita defined community as 'mums and dads and clubs ... and the schools are important too.' Others described the organised social activities within the community. Belonging to clubs gives the residents a sense of belonging that forms their closeness and sense of community.

In this study the locals saw the physical location as well as the social groups they participated in as the two factors that brought them together to experience a sense of community.

\section{Commitment to volunteering}

The sense of community is experienced not only through the geographical location and the sharing of interests but also through voluntary work. This is looking beyond their own needs to the greater good of the community. The Tuatapere participants have a strong community spirit amongst the residents. Donald and Robin recalled years involved with the voluntary ambulance service. Ngarita spent a good part of her life in community work and Helen gave of her time to the Resource Centre for 20 years.

In 1984 there was a flood that inundated the township and surrounding farmland. The community came together to assist wherever they could. Donald said:

The community just boxed together and went from farm to farm helping the farmers out as they didn't have any fences left. The community effort that went into that was amazing. That's when you find in rural areas that in a crisis they come out of the woodwork. 
This coming together at a time of crisis contributes to the sense of community of working together for the greater good. Donald spoke about this volunteer attribute being passed on to him by his parents:

Both my father and my mother were very active in the community...To be able to do things without having to be paid for it. If you don't get the volunteers in the small rural areas you won't exist. We survive on our own... still rely on outside help. We can't do it all on our own. But we all pitch in where we can.

The participants made reference to the new inhabitants in Tuatapere being the dairy workers who support the high technological mode of production that is required for the production of milk for the global market. The old ways of thinking are being challenged by the new realities that don't allow them to be involved in the community. How the new inhabitants are viewed by the settled inhabitants of the existing community depends on how they integrate themselves into the community. Helen stated, 'It seems that the dairy workers have such committed hours that they don't actually contribute too much around the town. There is not a lot of interaction and their farm workers are the same.' Margaret said:

...the dairying boom should be really good for us, those people aren't really tied to the community, some are good but others have absolutely no intention of becoming involved in the community. They are itinerant so they are only here for a short term and they move on.

Other more recent inhabitants to the township are people from overseas. Some, from Britain and Australia, have chosen to come to New Zealand and Tuatapere in particular for the physical beauty of the landscape, the lifestyle and the affordable housing. June said, 'We had a couple from Brisbane who recently bought a house and have done it up inside and are busy doing up the outside. They came for a quieter lifestyle and they say they love the place.' The community is not averse to welcoming others into their fold but there is an expectation of 'doing their bit' and contributing on a voluntary basis to the social and survival functioning of the township. This can be difficult for those whose occupation requires them to spend a majority of their time at their place of occupation and source of income for their family.

\section{Sense of self}

\section{Women's sense of self}

A sense of self identity is how the influences from our past and how views on our current situation are constructed and provide meaning. This meaning could be viewed as in conflict with beliefs and structures from previous generations. The struggle to gain an identity was referred to by Margaret, one of the participants of the study:

So for me living in a small town growing up in a small town, a fiercely National town politically, I believe a lot of the women were subservient. They were very pleased to stay at home on the farm and the only thing they had to worry about was making scones when the stock agent came. Whereas I grew up when that wasn't enough for me.

Margaret's consciousness was developing through the women's movement during the 1970s and her own development within the Playcentre movement and later with New Zealand Education Institute. Margaret identified her need for independence but that she was also in an economically dependent situation (Briar, 1992). Later when she was working in the 
school, teaching pottery to the children, she realised that she was in fact in an unpaid position as a woman with all her skills and that she was worth something:

One day I was there as a volunteer as a parent help taking pottery and I realised that I had 35 kids and not a teacher in sight. I felt that my time was worth something and so I negotiated to be paid and it kind of just grew from there really.

This line of thinking is aligned to the idea that women's voluntary work and the concept that work within the home and in the community should go unpaid, is challenged (McKinlay, 1992). She stated that in fact women's labour is hidden, yet policies are made that rely on the community to care for its own. 'Failing to take account of unpaid work has implication for the way we measure our economy' (McKinlay,1992, p. 74). The hidden unpaid work of those within the home and community is not identified within the country's economic planning. This caring and teaching role is not identified in monetary terms in the social services budget.

Ngarita showed her strong sense of independence and leadership skills in her many roles on local body groups within the community and her ability to confront and debate social and political issues. The strength and independence shown by these women continues into the present day. Helen notes how there has been a turnaround in the township in later years with women starting up and running businesses:

They have taken the lead. The men seemed to have got lost somehow along the way. They have got discouraged or disillusioned, they are not into new things. The women have taken up the cudgels.

The changing role of women, especially within the farming fraternity, affected the availability of a reserve army of labour. In the past women moved freely in and out of their carer, house-focused role, their farm helper role and their participation in voluntary community group role. In the present day, women's time and availability is limited due to their paid work commitments. This changing role of women in business in Tuatapere reflects the changes in wider society. Women have increasingly taken leading roles in the business and professional realms in New Zealand over the past 20 years.

Men's sense of self

For the male participants their sense of self related to their physical environment. It also related to their ages being 60 and over, and having been brought up in an era of being the head of the house, the breadwinner, the land owner and the decision maker. They said that Tuatapere was a 'man's world' and they were relating to the outdoor activities such as hunting and fishing and other sporting activities.

Participants' sense of self shows how the effect of the physical environment and community expectations impacted on their lives. The community norms and expectations and the changing role of women became a conflict for some. The many roles that women undertook both in the private and public sphere, saw their emerging strength in leadership within business and service groups in the community. The men showed an attachment to the area for what it could offer for their physical enjoyment. The participants emerged with a strong sense of self and a commitment to their own lives and the lives of the people in their community. 


\section{Access to services}

The participants' strong sense of self and community spirit were shown by the initiatives that they implemented to maintain a livelihood. The community's desire to continue to live in the environment that they have a strong affiliation with, enabled them to collectively pursue all possibilities. The residents' individual needs were balanced against the services and supports available to them within their community and the decisions made at a regional and national level that continued to impact on them.

This belief that there was an entitlement to services from government extended into the interview when the participants considered whether the government or local body decisions have assisted them to continue living in their township. They talked about the most recent decision impacting on their livelihood being a sewerage system for the township. Ngarita spoke about this decision making being at a regional and national level on economic grounds and not considering the social and financial impact on the town. She said that when they had planned the local dump for the town's rubbish they had an area on the outskirts of the town identified for the dump. They had planned for the gravel from the hole to be sold to pay the wages of a person to maintain the dump. However national government in Wellington decided that they needed all the local townships' waste to form the 'critical mass' to justify a regional dump.

\section{Research findings}

\section{Existence of a community spirit}

The community spirit was shown by the Tuatapere residents 'coming together' following the changes to their town in the 1980s. From their shared place of location, their shared value systems and their ability to assist they became involved to initiate new ideas or 'help out'. The survival of the community is seen as the people's ability to give of their time on a voluntary basis. Although the participants acknowledge this was a value passed down to them by their parents they state that there appears to be a diminishing commitment by the younger generation and newer residents to the area, to contribute to the functioning of the community in this way. If the basis of people's integration into a community is based on their ability or lack of ability to volunteer one wonders how the 'community spirit' is maintained.

The geographical attraction may well be the solution to the dwindling pool of volunteers and possible diminishing of the community spirit. It will of course depend on integration of newcomers into the community both in terms of how they contribute and how they are received by established residents. There may well be a new wave of settlement for the areas like Tuatapere. This therefore affirms that society is changing. New sets of values and beliefs can be introduced into a community. Future efforts to attract newcomers to the area need to examine the process of recruitment and the establishing of support within the settling process.

\section{Devolution}

Not only is a rural community expected to meet the social and recreational needs of its people but the expectation is that it meets the basic needs of its people as well. Today we live in a country with a 'safety net' of welfare, education and health systems. The government's decision to devolve social responsibilities back to communities is made on the assumption 
that people are available to give of their time to perform these tasks. As we have seen the rural communities have limited people available due to changes including depopulation and the need for people to be in paid employment.

In the education sector boards of trustees who make major decisions on the functioning of their schools do so on a voluntary basis. In the health sector families are expected to provide transport to members who live in areas with limited services so that they can access these services in larger cities. There is also an expectation of families taking care giving roles for those invalided or elderly. In the welfare sector the communities are being encouraged to support friends and families. Fifty years ago these expectations were part of the strong community ethos supported by the traditional values and beliefs of the citizens. In today's society, even if the caring ethos is present, the practicality of these expectations is logistically demanding on the community.

The residents of this study lived through an era of strong state intervention and support. Their expectations were that this would continue throughout their lives. This was not the case. The challenge for them is to find solutions to provide necessary services. If the gaps in community services are being filled by private enterprise, that possibly absolves the community from volunteering (if they are able to in the first place). Volunteering contributes to the existence of a community spirit and if this is weakened then the glue that holds it together starts to dissipate.

The challenge is to find a balance of private sector input but also have a large enough pool of volunteers with time and a willingness to maintain the community spirit. The solutions to any future gaps in services need to be considered carefully in consultation with the community.

\section{Conclusion}

While this study was limited to exploring a defined topic, it exposes the range of potential research available for people interested in recording change in communities. It also signals there is a wide range of expertise and knowledge available in communities which can be recorded and made available for future researchers. From these insights two recommendations for future research emerge:

- That rural communities continue to value social and historical research by conducting community research recording the changes in New Zealand life.

- That further research be conducted on the impact of social change, specifically on one's sense of community in relation to the ability to volunteer.

Most importantly, such research allows us to see through the eyes of those we walk alongside as we carry out our roles as social workers.

The changes that have impacted on the residents of Tuatapere have been met as a challenge by the community. Services that once were available to them have been withdrawn but they have gathered their resources to establish sufficient services to meet their needs. The final words on the Tuatapere township community are related by Ngarita and Margaret. 
The town celebrated its 100 years about three years ago. We had the minister from Te Anau and he brought five stones out of the river. He said this is the town's generations and he spoke and it was a most interesting address that. The five stones. It was a very apt way of putting it.

You have to like it here... I like the community. I love the little town... It's the environment and it's the people that you know. One day you wake up and you know that you are some of the older people in the town... I think it is important for people to have roots.

\section{References}

Atkinson, R. (1998). The life story interview: Sage University papers series on qualitative research methods, 44. Thousand Oaks, CA: Sage.

Boston, J., \& Dalziel, P. (Eds). (1992). The decent society. Auckland: Oxford, University Press.

Briar, C. (1992). Women, economic dependence and social policy. In C. Briar, R. Munford \& M. Nash (Eds). Superwoman where are you? Social policy and women's experience (pp. 41-69). Palmerston North: The Dunford Press Limited.

Cole, A. L., \& Knowles, J. G. (2001). Lives in context: The art of life history research. Oxford: Rowman \& Littlefield.

Connolly, M., Crichton-Hill, Y., Ward, T. (2006). Culture and child protection reflexive responses. London: Jessica Kingsley Publishers.

Dalziel, R. (1986). The Colonial Helpmeet. Women's role and the vote in nineteenth-century New Zealand. In B. Brookes, et al. (Eds.), Women in history. Essays on European women in New Zealand (pp. 55-68). Wellington: Allen and Unwin/ Port Nicolson Press.

Fook, J. (1996). The reflective researcher: Social workers' theories of practice research. Australia: Allen \& Unwin.

Houghton, R.M., King, A., Piper, R.K. (1996). Land use and community in rural Southland: A summary of information on economic and social change since 1970. Wellington: MAF Policy Technical Paper 97/6.

Howden, S.I. (2001). Rural communities: Expressions of 'community' in context: Narratives from the Lower Mataura Valley in Southland. Unpublished master's thesis. Palmerston North: Massey University.

James, B., \& Saville-Smith, K. (1989). Gender culture \& power. Auckland: Oxford University Press.

Joseph, A.E., \& Chalmers, A. I. (1995). Growing old in place: A view from rural New Zealand. Health E Place, 1(2), 79-90.

Maguire, M. (1999). Rural masculinity, 1980-1995. Palmerston North: Massey University.

McKinlay, R. (1992). Women and unpaid work. In C. Briar, R. Munford \& M. Nash (Eds). Superwoman where are you? Social policy and women's experience (pp. 41-69). Palmerston North: The Dunford Press Limited.

Patton, M.Q. (1990). Qualitative evaluation and research methods, (2nd Ed). London: Sage.

Pitt, L.M. (1998). Patriarchs, paddocks and the personal: Five women from the Wharehuia/Te Popo district talk about their lives. Unpublished masters thesis. Palmerston North: Massey University.

Shirley, I. (1994). Social policy \& social planning. In P. Spoonley, D. Pearson, I. Shirley, (Eds). New Zealand sociological perspectives. Palmerston North: Dunmore Press.

Southland District Council. (1995). Tuatapere area concept development plan. Invercargill: Southland District Council.

Statistics New Zealand. (2006). http: / / www.stats.govt.nz.

Taylor, Baines \& Associates. (1998). Resource, community formation \& change. Christchurch: Taylor, Baines \& Associates.

Templeton, A. (1995). Southwest sawmills. Invercargill: Southland District Council. 